\title{
Analysis on Status of Information Technology Cognition of Freshmen in Higher Vocational College- A Study of Tianjin
}

\author{
Shuzhen Du \\ School of Information Technology Engineering, \\ Tianjin University of Technology and Education, \\ Tianjin, 300222, China \\ dushuzhen_love@126.com
}

\begin{abstract}
The study carried out with research perspective from learners' cognitive status quo of the computer, based on the hybrid research methods and used random cluster sampling. The author distributed an open and anonymous survey questionnaire to freshmen, who come from five higher vocational college of Tianjin, and then used statistical tools SPSS to quantify the questionnaire. This study shows that there are three cognitive types of freshmen before learning the basic computer course. They are Geographic Cognition, Sexual Cognition and Hybrid Cognition. The paper analyzed the extent of three cognitive types affecting on information technology cognition of freshmen. The study implemented from four aspects: learners' basic situation of using the computer, subjective awareness on the importance of computer, the basic situation of computer skills and the expectation for the teaching of computer course. Finally, the paper tries to provide the reference about teaching starting point design for computer based public required course in higher vocational colleges.
\end{abstract}

Keywords-Freshmen in higher vocational college; Status of information technology cognition; Survey questionnaire; Computer basic course

\section{INSTRUCTIONS}

The widespread application of information technology, promotes effectively the change of the way to the people's lives, learning and work, puts forward new challenge to vocational education informatization reform and talent cultivation. "Development plan of education informatization decade (2011-2020)," pointed out: school should strengthen computer application basis teaching, as the public required course, open related elective courses actively, improve the students' key ability of information technology and the comprehensive information literacy through various channels, promote vocational education informatization construction. At the same time, higher vocational education, which presents the directional property of the training objective and the marketability of professional settings, asks the vocational students for a more modern requirement, ${ }^{[1]}$ they should master advanced information technology as much as possible, which can convert into productivity directly.

The study carried out with research perspective from learners' cognitive status quo of the computer ${ }^{[2]}$, based on the

\author{
Guangran Liu \\ School of Information Technology Engineering, \\ Tianjin University of Technology and Education, \\ Tianjin, 300222, China \\ liuguangran@163.com
}

hybrid research methods ${ }^{[3][4]}$ and used random cluster sampling. The author distributed an open and anonymous survey questionnaire to freshmen, who come from five higher vocational college of Tianjin, and then used statistical tool $\operatorname{SPSS}^{[5][6]}$ to quantify the questionnaire. Geographic Cognition determines students' perception on the time of contacting the computer initially, the major place and purpose to use computer at present and the importance of the computer for future study and work. Sexual Cognition determines students' perception on the computer tool itself, its composition and working principle as well as being interesting in the content of the basic computer course. Hybrid Cognition, composed by Geographic Cognition and Sexual Cognition integrating into the factor, whether students have a computer, influences students' information technology cognition. Finally, the paper tries to provide the reference about teaching starting point design for computer based public required course in higher vocational colleges.

\section{SURVEY DESIGN}

This questionnaire extracts five higher vocational college of Tianjin, including Tianjin Light Industry Vocational Technical College, Tianjin Sino-German Vocational Technical College, Tianjin Modern Vocational Technology College, Tianjin Electronic Information College and Tianjin vocational Institute. It involves in the major containing electronic information engineering technology, aircraft manufacturing technology, mold design and manufacturing, software technology, hydraulic and pneumatic technology, etc.

The survey issues 633 questionnaires in total. 626 of them are effective, the others are noneffective. Questionnaire uses an anonymous way and investigated the status of information technology cognition of freshmen in higher vocational college. After sorting and analyzing, the study, through using SPSS, conducts on an internal consistency Reliability Analysis to the questionnaire. The results showed that the internal consistency reliability coefficient of the questionnaire is 0.602 , which is greater than 0.6 , indicating that questionnaire is valid, the reliability of the questionnaire can be considered better.

This article uses the statistic tool SPSS to quantify the topic of the questionnaire to make statistical analysis. The 
questionnaire was analyzed from three factors, including sex, family location and having a computer. The data is processed through preliminary Descriptive Statistics and Crosstabs outputting Chi-square results. The results reveal that the three factors have vary degrees correlation with the respondent's information technology cognition. There may exist interaction when three factors acting on each observed variables. At the same time, on the description, which individual factors effect on the relevant variables, is not enough to point out that the reliability of the problem. Besides, observed variables are quantitative, belong to discrete variables, so Analysis of Variance (ANOVA) is used for each observed variables.

\section{DATA ANALYSIS}

The survey includes 454 boys, which accounts for $72.5 \%$ of the total number of investigation, and 172 girls, which accounts for $27.5 \%$. 399 of them come from rural areas, accounting for $63.7 \%$ of the total number of investigation; 71 people from the county, accounting for $11.3 \%$ of the total number; 55 people from small and medium-sized cities, accounting for $8.8 \%$ of the total number of investigation; 21 people from the provincial capital city, accounting for 3.4\%; 80 people from the municipality directly under the central government, accounting for $12.8 \%$. $49.4 \%$ of respondents do not have a computer, $50.6 \%$ of the students have a computer.

\section{A. The Basic Situation of Using Computer}

By Referencing the time of computer popularization in China, the questionnaire sets up four options, including elementary school, junior high school, high school and college, aiming at the problem about the freshmen, who come from higher vocational colleges, " the time of contacting the computer initially". Result getting from Oneway ANOVA reveals that the homeplace affects the freshmen in the time of contacting the computer initially, the current purpose and main place of using the computer and main site. With the rapid popularization of information technology, the origin of computeracy has lots, such as the information technology course, parents, friends, self-study, games, multi-media channels, etc. Multi-factor Variance test result shows that the $\mathrm{p}$ value is 0.028 , under the significance level of 0.05 , that sex, having a computer and homeplace three factors work together to respondents, influencing the computeracy of respondents. As shown in Table 1.

\section{Levene's Test of Equality of Error Variances}

TABLE I DEPENDENT VARIABLE: THE ORIGIN OF COMPUTERACY

\begin{tabular}{|c|c|c|c|}
\hline F & df1 & df2 & Sig. \\
\hline 3.323 & 19 & 606 & .028 \\
\hline
\end{tabular}

\section{B. The Subjective Awareness on the Importance of}

\section{Computer}

9.6\% of the students thought that the computer isn't useful, $24.3 \%$ said they use computer occasionally in life, $31.8 \%$ think the computer is often used in study and life, and the other $34.3 \%$ said the computer is very important in the position of study and life. One-way ANOVA shows that sex works on observed variables alone. Moreover, $3.2 \%$ of the students think the computer has no impact on the later work and study, computer skills is additional; $7.8 \%$ said the computer has a bit of influence in later work and study; $28.9 \%$ think the computer has a certain influence on future work and study; $60.1 \%$ said the computer for future study and work is very influential, homeplace is the main factor for observed variables having significant difference. In the problem about the degree of being interested in the computer itself, Levene's test of equality of error variances shows that, under the significance level of 0.05 , the observed variables in sex, having a computer and homeplace three factors exist significant difference, when they effecting at the same time. As shown in Table 2.

\section{Levene's Test of Equality of Error Variances ${ }^{a}$}

TABLE 2. DePENDENT VARIABLE: THE DEgREE OF INTERESTING IN COMPUTER

\begin{tabular}{|c|c|c|c|}
\hline F & df1 & df2 & Sig. \\
\hline 2.092 & 18 & 607 & .005 \\
\hline
\end{tabular}

\section{The Basic Situation of Computer Skills}

Typing speed per minute of the freshmen is the basic computer skill. Levene's Test of Equality of Error Variances showed that sex, familyplace and having a computer three factors influence on the observed variables at the same time. As shown in Fig. 1. When getting enrolled in college initially, $23.5 \%$ of the students said they are not clear about the cognition of computer composition and working principle, $59.6 \%$ said they has a bit of cognition and understanding, $12.8 \%$ express that they have a pretty understanding, only $4.2 \%$ have a comprehensive understanding. One-way ANOVA shows, sex effects observation variable separately, interaction factors is not obvious.

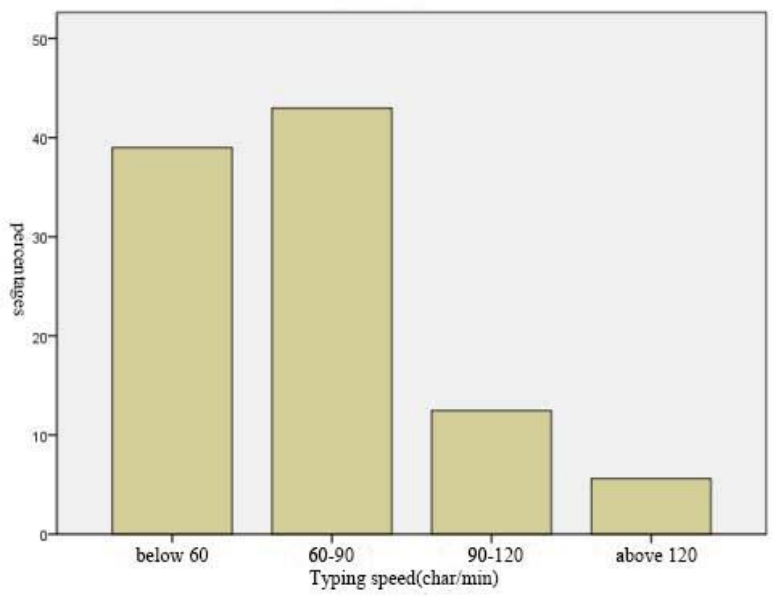

Fig. 1 " Typing speed " frequency table

\section{The Expectation for the Teaching of Computer Course}

The intention of survey works on interest in computer basic content. Survey data shows that sex factor determines the cognition about the subjects to the observed variables. What expectations would you like as a result after learning the computer basic course, namely the Curriculum Expectation. The result of multivariate ANOVA shows that 
sex, homeplace and having a computer three factors affect the choice of the respondents on observed variables at the same time, as shown in table 3. Besides, Levene's Test of Equality of Error Variances shows that sex and homeplace interact respondents to determine the expect degree of the teaching purpose of computer course. As shown in Fig. 2.

\section{Levene's Test of Equality of Error Variances ${ }^{\text {a }}$}

TABLE 3. DEPENDENT VARIABLE: EXPECTATION FOR COMPUTER COURSE

\begin{tabular}{|c|c|c|c|}
\hline F & df1 & df2 & Sig. \\
\hline 2.403 & 19 & 606 & .001 \\
\hline
\end{tabular}

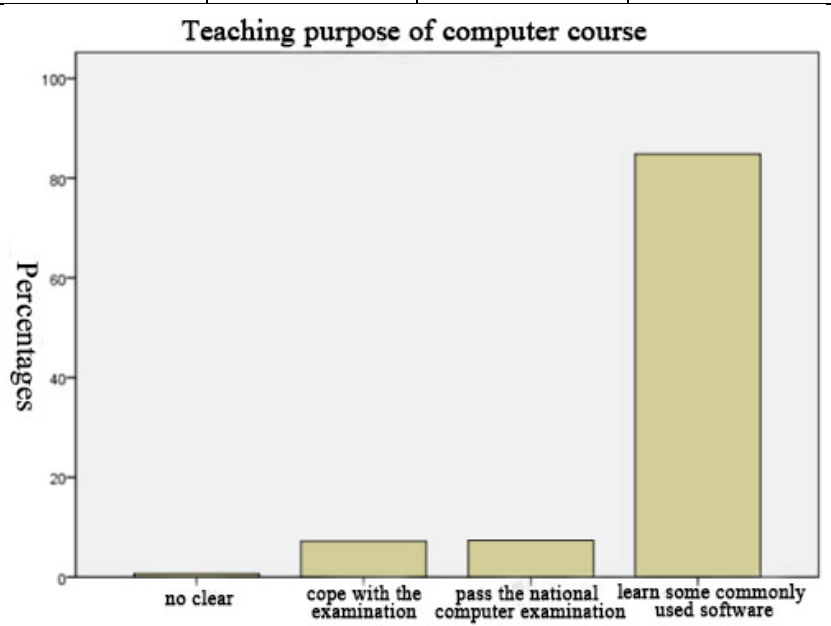

Fig. 2 " Teaching purpose of computer course " frequency table

\section{STATUS AND IMPLICATION}

\section{A. Status}

Through studying and analyzing of the survey data, the cognition of freshmen in higher vocational have more or less cognition before learning basic computer courses. The cognition was divided three types: Geographic Cognition, Sexual Cognition and Hybrid Cognition. Geographic Cognition determines students' perception on the time of contacting the computer initially, the major place and purpose to use computer at present and the importance of the computer for future study and work. Sexual Cognition determines students' perception on the computer tool itself, its composition and working principle as well as being interesting in the content of the basic computer course. Hybrid Cognition, composed by Geographic Cognition and Sexual Cognition integrating into the factor, whether students have a computer, influences students' information technology cognition, forms the students' cognition of information technology at eventually.

Geographic Cognition. Most of the students in primary schools have begun to contact the computer, but a first-time of contacting computer still mainly depends on students' homeplace. Whatever the major place and purpose to use computer at present or the importance of the computer for future study and work, homeplace is the dominant influence factor.
Sexual Cognition. The cognition of freshmen is determined by sex in certain aspects of computer. The decisive factor is sex. Survey result shows that students enter university initially, the sex factor is the dominant factor that students cognize the importance of computer tools itself as well as composition and working principle of the computer. In addition, sex also affects the students' interest in the basic content of the computer.

Hybrid Cognition. The interaction of homeplace and sex influence the students' awareness about the teaching purpose of the computer course. The interaction of homeplace, sex, and having a computer affect the source of the computeracy, further affect the degree of students' interest in computer itself. Students' typing level and expectations for the computer course is also impacted by the three factors.

\section{B. Implication}

First, freshmen from the higher vocational colleges have been contacted with the computer before going to college, but there is a shortage of phenomenon like the purpose on using the computer no strong, lack of awareness on the influence of the computer to the later work and study. Therefore when doing the teaching on computer basic theory, in view on the students of Geographical Cognition, we can add some practical and advanced knowledge of computers, popularizing the students' cognition that the computer can be widely applied, fused and popularized in daily life. Students are guided to the attitude on using computer rightly, impacted subconsciously to choose the place and purpose to use a computer and improved the cognition about the importance of the computer in the later study and work. Teaching workers should avoid the use of pure theory explaining pure theory, the theory of knowledge should be linked with real life, computer symbolic event evolution. Teaching should add some video display about computer application technology. The teaching content should keep up with the developing speed of computer, making students to have a systematical cognition on the development of information technology.

Second, some students have a shortage of awareness on the importance of computer tools in daily life, the degree of the computer composition and the rational knowledge, the content of computer foundation course. There is no clear tendency of learning. And these problems are connected mainly with regional factors. Aiming at these students, when doing the teaching of computer basic courses, teaching workers should deliver students the importance of computer tools through the actual case. When explaining systematical knowledge of the computer, teaching workers can use the three-dimensional virtual technique to display computer assembly. Furthermore, you can increase the practice class. Students could have a clear cognition on the composition and working principle of the computer through the actual operation. Students' interest in computer basic course content can be further improved.

Third, the source of students' computer knowledge is mainly composed with variety of factors. At present, many problems exist. The overall level of the typing speed is not high, the purpose of expectation on computer courses is not 
strong, there are fuzzy recognition of some students on courses in computer. Teaching workers should organize the students more practical operation on computer, you can increase students' skills to operate the computer by hands-on exercises such as typing games and demonstrating. In addition, you can increase the enthusiasm of students for study by setting the course for credit or recording of student performance. In the design of teaching situation, you can stimulate students' expectations for computer courses by the transfer of computer course teaching, as a whole, you should guide students to have a correct understanding of computer course.

\section{CONCLUSION}

The study implemented with research perspective that freshmen, who will begin formal learning in the higher vocational colleges, are not zero cognitive to the computer. Questionnaires were issued and survey data were quantified and analyzed. Then, the cognition quo of information technology was divided three types: Geographic Cognition,

Sexual Cognition and Hybrid Cognition. The paper analyzed the extent of three cognitive types affecting on information technology cognition of freshmen. Finally, according to freshmen' cognition quo of information technology while enrolling initially, the paper tries to provide the reference about teaching starting point design for computer based public required course in higher vocational college. Through this study, the students' key ability of information technology and the comprehensive information literacy can improve through various channels, and accelerate the vocational education informatizative construction.

\section{REFERENCES}

[1] Xiaonian $\mathrm{Li}$, "Research on the Problems and Countermeasures of Information Quality Education in Higher Vocational Colleges," in Journal of the Staff and Worker's University, vol 4, pp. 113-117 , August 2013.

[2] Jing Wang, Y.D., “On High School Students' Cognitive Status before Learning Information Technology: Research on Psychology in Learning Information Technology Based on CTCL(1)" in Journal of Distance Education, vol 5, pp. 56-62, October 2012.

[3] Yuqi Dong, J.W., L.Y., J.B., “CTCL:A New Paradigm of Educational Technology Research(1):The Basic Conception and Preliminary Study," in Journal of Distance Education, vol 2, 3-14, February 2012.

[4] Qiaohong Yao, J.Y., C.X., "Review on Education Technology Research Paradigm,” in E-education Research, vol 6, pp. 64-67, June 2009.

[5] Hongpo Zhang, H.Z., SPSS Statistical Analysis and Practical Book, Beijing: Tsinghua University Press, 2012.

[6] Jianping Zhu, K.F, G.Z., SPSS Statistical Analysis and Application. Beijing: Capital University of Economics and Business Press, 2013. 